\title{
RESPOSTAS ADAPTATIVAS DE PEIXES A ALTERAÇÕES AMBIENTAIS DE TEMPERATURA E DE OXIGÊNIO DISSOLVIDO
}

\author{
(Adaptive responses of fishes to environmental changes on temperature and \\ dissolved oxygen)
}

Thayzi Oliveira Zeni, Antonio Ostrensky, Gisela Geraldine Castilho westphal ${ }^{1}$

1Correspondência: thayzi@yahoo.com.br

RESUMO: Cada vez mais, os ambientes aquáticos têm sofrido pressões tanto de origem natural quanto antrópica. Por estes motivos os organismos que habitam estes ecossistemas são forçados a se adaptar às novas condições ou poderão ser extintos. O estudo para compreensão destas transformações ambientais pode ser feito por meio do uso de animais indicadores, dentre os quais os peixes se destacam. Isto porque os peixes refletem as modificações ocorridas no ambiente aquático por meio de respostas adaptativas tão variadas quanto: (1) ajustes fisiológicos e bioquímicos quando peixes são expostos a diferentes temperaturas e (2) por alterações identificadas em peixes submetidos a baixas concentrações de oxigênio dissolvido na água. Este estudo foi desenvolvido com o objetivo de avaliar de que maneira os peixes podem ser utilizados como organismos indicadores das alterações ambientais relacionadas à temperatura e à variação de oxigênio dissolvido e entender melhor a interação destes animais com o ambiente.

Palavras-chave: ambiente aquático; hipóxia

ABSTRACT: Aquatic environments have been suffered several kinds of transformations both natural and mainly anthropogenic origin. The organisms inhabiting these ecosystems are forced to adapt to new conditions or these species will be extinct. The study to understand these environmental changes can be done through the use of animals indicators, among which the fish stand out. The fish reflect the changes in the aquatic environment through adaptive responses as varied as: (1) physiological and biochemical adjustments when fish are exposed to different temperatures and, (2) through alterations identified in fish subjected to low concentrations of dissolved oxygen in the water. This study was carried out to evaluate how the fish can be used as indicator organisms of environmental changes related to variations in temperature and dissolved oxygen and to better understand the interaction of these animals with the environment.

Key Words: aquatic environment; hypoxia 


\section{INTRODUÇÃO}

Em qualquer meio onde existam variações ambientais, as adaptações surgem como uma alternativa para assegurar a sobrevivência, a reprodução, o desenvolvimento, a distribuição geográfica e a diversificação das espécies (Peres-Neto, 1999; Randall, 2006).

Muitas das pesquisas que abordam as formas de adaptação das espécies a ambientes impactados antropicamente têm utilizado organismos aquáticos como modelo de estudo. Isto porque, dentre as consequências das alterações ambientais, estão a alteração das variáveis determinantes da qualidade da água, a perda da biodiversidade aquática em função da desestruturação do ambiente físico e químico e a alteração da dinâmica natural das comunidades biológicas (Currie e Tufts, 1997; Goulart e Calistto, 2003).

O ambiente aquático é extremamente dinâmico e os organismos que nele vivem enfrentam alterações ambientais dificilmente enfrentadas por animais terrestres, como mudanças rápidas ou extremas de temperatura, na concentração de oxigênio dissolvido, no $\mathrm{pH}$, na concentração e nos tipos de íons
(Mariano, 2006). Variáveis como estas podem ocasionar estresse e reduzir a habilidade dos animais em manter sua homeostase (Mariano, op. cit.). Essas alterações ambientais são ainda mais críticas em ambientes aquáticos sobre influência de atividades antrópicas de origem biológica (lançamento de efluentes domésticos e industriais), física (lançamento de resíduos radiativos ou de detritos inertes) e/ou química (lançamento de resíduos industriais e de embarcações, por exemplo) (Santana, 2008).

Dentre as variáveis ambientais mencionadas, a temperatura e as concentrações de oxigênio são parâmetros que afetam diretamente os processos fisiológicos de todos os organismos aquáticos (Munday et al., 2009).

A temperatura de ambientes aquáticos pode ser alterada de maneira aguda, como por exemplo, quando indústrias despejam água aquecida ou resfriada em rios e lagos. Também pode ser alterada a longo prazo, como é o caso do aquecimento global. De acordo com os cenários projetados pelo IPCC (2007), a temperatura média global deve aumentar entre $2,3^{\circ} \mathrm{C}$ e $4,5^{\circ} \mathrm{C}$ até $\mathrm{o}$ ano de 2100 se comparada ao período préindustrial. 
Carneiro (2002) comenta que a construção de barragens interrompe o fluxo natural do curso d'água, acarretando em variações no regime fluvial, transformando zonas de correntezas em ambientes lênticos. Além dessas alterações drásticas dos padrões locais de circulação, isso também pode afetar a temperatura e, principalmente, a concentração de oxigênio dissolvido em ambientes aquáticos. Esta falta de circulação contribui para que ocorra a formação de termoclinas e oxiclinas. Fiorucci e Filho (2005) ainda comentam que a construção de represas sobre áreas de florestas podem resultar na formação de lagos com alta demanda bioquímica de oxigênio. Nessas represas, a grande quantidade de fitomassa inundada, ao se decompor, gera elevados déficits de oxigênio.

Casagrande (2006) comenta que reduções na concentração de oxigênio dissolvido em ambientes aquáticos podem ocorrer quando quantidades significativas de matéria orgânica são incorporadas a eles. Essa situação ocorre normalmente com o lançamento de esgotos domésticos e de efluentes industriais ricos em matéria orgânica nos corpos d'água.

Desta forma, seja por causas naturais ou antropogênicas, os ambientes aquáticos estão, cada vez mais, sendo submetidos a processos que levam à alterações dos padrões locais ou regionais de temperatura e de oxigênio dissolvido.

Nessa linha de pesquisa, na qual organismos aquáticos são afetados por alterações ambientais diversos grupos tem sido alvo de estudo, tais como: microalgas (Morais e Costa, 2008; Johnson et al., 2009; Lohbeck et al., 2012), macroinvertebrados (Johnson et al., 2009); anêmonas (Black et al., 1995; Choresh et al., 2001; Goldstone, 2008), moluscos bivalves (Clegg et al., 1998; Buckley et al., 2001; Lacoste et al, 2001; Brown et al., 2004; Fabbri et al., 2008; Cho e Jeong, 2012), gastrópodes (Tomanek, 2002; Tomanek e Sanford, 2003), crustáceos (Ravaux et al., 2003; Ravaux et al., 2007; Fernandes, 2010) e peixes (Iwama et al., 1998; Iwama et al., 1999; Iwama et al., 2004; Breau et al., 2007; Johnson et al., 2009).

Segundo Al-sabti e Metcalfe (1995), além de geralmente apresentarem interesse econômico, o uso de peixes é frequente nesse tipo de estudo pois estes apresentam respostas toxicológicas similares àquelas apresentadas pelos vertebrados superiores. Além disso, esses autores citam que os peixes indicam o potencial de exposição de populações humanas a 
genotóxicos químicos e também estão entre os maiores veículos de transferência de contaminantes para humanos.

Este estudo foi realizado com o objetivo de avaliar quais são os mecanismos adaptativos dos peixes às alterações ambientais diretamente relacionadas à temperaturas e ao oxigênio dissolvido.

\section{DESENVOLVIMENTO}

1- ADAPTAÇÃo de PEIXES A VARIAÇÕES DE TEMPERATURA

De acordo com Dong e Somero (2008) uma das alterações em escala global mais discutida atualmente, 0 aquecimento global, afetaria diretamente as espécies e as comunidades de peixes. Assim, é de suma importância entender como as condições ambientais variam no espaço e no tempo bem como de que maneira os organismos respondem a estas variações (Tewkbury et al, 2008).

Mudanças de temperatura de alguns poucos graus Celsius podem influenciar os principais processos fisiológicos dos peixes, tais como a taxa de crescimento, a capacidade de natação e o desempenho reprodutivo. Estes, por sua vez, parecem ser particularmente sensíveis à variação da temperatura durante as fases de ovos e larvas (Munday et al., 2009).

Como os peixes são organismos ectotermos, sua temperatura corpórea reflete a temperatura do ambiente que 0 circunda (Randall et al., 2000). Contudo, alguns peixes conseguem reter calor em algumas partes do corpo (músculo, olhos, cérebro e vísceras) (Pough et al, 2003). Esta capacidade de retenção de calor habilita as espécies que a possuem de desenvolver uma natação rápida e contínua, com uma eficiente contração muscular. Além disso, estabiliza o metabolismo e as funções sensoriais e digestórias (Baldisserotto, 2009).

Porém, mesmo nesses casos, assim como naquelas espécies que não apresentam qualquer mecanismo de retenção de calor, a temperatura da água constitui-se no mais importante fator para o controle dos processos fisiológicos em peixes (Brian et al., 2008). Os limites de tolerância à temperatura para uma dada espécie, entretanto, não são fixos. A exposição a uma temperatura próxima da letal frequentemente induz a adaptação, de modo que uma temperatura anteriormente letal passe a ser tolerada (Schmidt -Nielsen, 1999; Baldisserotto, 2009). 
Dentre as adaptações correlacionadas à temperatura, podemse distinguir aquelas que afetam a sobrevivência do animal diante de índices extremos (adaptações de resistência) e aquelas que afetam as capacidades fisiológicas diante de temperaturas não extremas (adaptações de capacidade) (Hochachka e Somero, 2002).

\subsection{Ajustes fisiológicos e} bioquímicos dos peixes frente a altas temperaturas

Quando ocorrem aumentos abruptos de temperatura em ambientes aquáticos, os peixes geralmente elevam suas frequências cardíaca e respiratória, devido ao aumento de seu metabolismo (Baldisserotto, 2009). A carpa comum (Cyprinus carpio) é um exemplo desta situação, pois em ambientes cuja temperatura esteja entre 6 e $15^{\circ} \mathrm{C}$ acima da faixa de conforto, ela é capaz de aumentar 0 volume de sangue bombeado pelo coração e elevar sua frequência cardíaca. Isso ocorre devido há um aumento na taxa de despolarização das células marca-passo do coração (Baldisserotto, 2009). Esse aumento na frequência cardíaca é essencial para compensar o aumento das taxas metabólicas em geral.
Outro tipo de ajuste que os peixes podem realizar é a reorganização do metabolismo celular. Quando são expostos a temperaturas diferentes das que estão acostumados, eles utilizam vias metabólicas diferentes (Randall et al., 2000). De acordo com Baldisserotto (2009), podem ocorrer mudanças na síntese de enzimas, na concentração de substrato e/ou produtos das rotas metabólicas e de moduladores de reações enzimáticas. Pode ocorrer também a substituição de uma forma molecular com mesma especificidade enzimática (isoenzima) por outra, dependendo da temperatura, visto que existe uma isoenzima específica para cada temperatura. Avrora (1984) comenta que o processo de condução nervosa é extremamente sensível a alterações de temperatura e que a composição dos ácidos graxos de gangliosídeos cerebrais correlaciona-se com a temperatura ambiental. De acordo com Prosser (1967) os processos de adaptação térmica em peixes estão relacionados às alterações funcionais do sistema nervoso. As funções sinápticas são extremamente sensíveis a alterações de temperatura, de modo que a sinapse é considerada a principal área adaptativa do sistema nervoso. 
Estudos realizados por Roots (1968 citado por Breer e Rahmann, 1976) com exemplares de goldfish (Carassius auratus) sugerem que ocorram modificações nos fosfolipídios de membrana quando os animais são expostos a temperaturas fora da faixa de conforto. Essas modificações permitiriam a manutenção da fluidez e da permeabilidade das membranas, melhorando o funcionamento do sistema nervoso destes animais. Hochachka e Somero (1973) também verificaram que a composição fosfolipídica das membranas celulares em tecidos nervosos de animais que vivem em baixas temperaturas é mais insaturada do que daqueles que vivem em altas temperaturas. Essas mudanças, assim como as mencionadas por Roots (1968 citado por Breer e Rahmann, 1976), são importantes para manter a viscosidade das membranas celulares.

\subsection{Adaptações dos peixes frente a baixas temperaturas}

Quando a temperatura da água decai, os peixes imediatamente tendem a reduzir as suas taxas metabólicas, permitindo uma economia de reservas corporais em ambientes desfavoráveis, fator este importante, pois em baixas temperaturas a disponibilidade de alimento pode ser reduzida (Pough et al., 2003). Exemplares de enguia americana (Anguilla rostrata), em águas abaixo de $8^{\circ} \mathrm{C}$, param de se alimentar e se enterram na lama. A maioria das espécies de peixe, entretanto, não se enterra quando apresentam torpor ao frio, apenas ficam imóveis para reduzir o gasto energético (Baldisserotto, 2009).

Algumas alterações no

metabolismo celular podem fazer com que as substâncias de reserva mudem. Com uma redução de temperatura, por exemplo, pode ocorrer um aumento nas reservas de glicogênio e uma diminuição dos triacilgliceróis no fígado de trutas arco-iris (Oncorhynchus mykiss). Neste caso, os lipídeos são usados para fornecer energia e o glicogênio é armazenado (Baldisserotto, 2009).

Schimidt-Nielsel (1999) explica que os organismos que habitam regiões temperadas e polares podem desenvolver tal tolerância ao frio a ponto de conseguirem sobreviver ao congelamento prolongado e impedirem a formação de gelo em seu corpo. A maioria das espécies, entretanto, podem ser tolerantes ao congelamento, mas morrem se houver formação de gelo em seu sangue ou tecidos.

Pode-se considerar, portanto, que a ameaça à vida nas baixas temperaturas não é apenas o frio, mas 
também a impossibilidade de evitar a formação de gelo nos tecidos. Como as células e os corpos dos animais são compostos por grande quantidade de água, o gelo pode ser letal porque sua formação perturba o equilíbrio entre os fluidos externos e internos das células, o que resulta em encolhimento celular e dano irreversível aos tecidos afetados (Verde et al., 2011). Para que isso não ocorra, algumas espécies produzem glicoproteínas anticongelantes (Verde et al., 2011). Estas proteínas são uma família de polímeros produzida no tecido pancreático e na porção anterior do estômago. $O$ sangue e fluídos tissulares dos peixes possuem estes componentes anticongelantes, os quais impedem a adição de moléculas da água á matriz de cristais de gelo e, portanto o seu desenvolvimento. De acordo com Verde et al. (2006) peixes que habitam os dois polos possuem estas glicoproteínas e estas constituiriam um clássico exemplo de adaptação independente.

Segundo Prisco et al. (1998), a primeira glicoproteína anticongelante foi descoberta no peixe antártico Pseudopleuronectes americanus. De acordo com os autores, foram descobertas três tipos adicionais de GA's, sendo diferenciadas pelas estruturas secundárias e terciárias.
Wohrmann (1996) comenta que exemplares de 37 espécies antárticas, representantes

Nototheniidae, das famílias Bathydraconidae, Muraenolepididae.

Zoarcidae e Artedidraconidae, Channichthyidae, Liparididae, apresentavam Myctophidae, proteínas anticongelantes, sendo que a concentração destas varia de acordo com a temperatura do ambiente.

Outro exemplo de adaptação a baixas temperaturas, que pode ser observado em teleósteos da família Channichthyidae (icefish), é a perda do gene codificador da hemoglobina (Verde et al., 2006).

Embora o oxigênio possa ser transportado livremente na sua forma dissolvida, grande parte dos animais faz uso de um ou mais tipos de proteínas carreadoras para transportar o oxigênio até os tecidos. Quando comparadas às espécies temperadas e tropicais, os nototenióides, peixes da região Antártica, possuem reduzida concentração de hemoglobinas. Peixes da família Channichthyidae, por sua vez, não apresentam hemoglobina. Todas as espécies de icefish (peixes-do-gelo) não possuem hemoglobinas e muitas também não produzem mioglobinas. Em exemplares destas espécies, o transporte de oxigênio aos tecidos 
ocorre por meio de um gás fisicamente dissolvido no plasma (Verde et al., 2011).

\section{ADAPTAÇÃO DOS PEIXES A AMBIENTES DE HIPÓXIA}

Dentre os gases dissolvidos na água, o oxigênio é um dos mais importantes na dinâmica e na caracterização dos ecossistemas aquáticos (Esteves, 1998).

As principais fontes de oxigênio da água são a atmosfera e a fotossíntese. Por outro lado, as perdas de oxigênio são causadas pela decomposição da matéria orgânica, perdas para a atmosfera, respiração de organismos aquáticos e pelo aumento da temperatura ambiente (Baldisserotto, 2009). Conforme a temperatura da água aumenta, a disponibilidade de oxigênio diminui, pois a solubilidade (lei de Henry) e o percentual de saturação do oxigênio caem. Além disso, a elevada atividade biológica em altas temperaturas tende a reduzir drasticamente a concentração de oxigênio, especialmente em corpos d’água de pequenas dimensões. Consequentemente, em altas temperaturas os peixes necessitam de mais oxigênio, embora este tenda a se encontrar menos disponível no ambiente (Powers et al., 1978). Por esta razão algumas espécies se adaptaram evolutivamente a viver em condições de hipóxia. A carpa Cyprinus carpio, por exemplo, é capaz de sobreviver até seis meses em águas com baixa temperatura e ausência de oxigênio dissolvido, respirando diretamente 0 oxigênio atmosférico. O peixe dourado (Carassius auratus) e o peixe sapo (Opsanus tau) também suportam condições de anóxia (Heath, 1995).

Porém, como regra geral, uma adequada concentração de oxigênio dissolvido nos ambientes aquáticos é vital para a sobrevivência e para 0 crescimento dos peixes. Mas não apenas as condições de hipóxia podem ser prejudiciais, mas também as de hiperóxia, uma vez que ambas podem provocar alterações na estrutura de lipídeos, proteínas e no próprio DNA dos peixes (Liepelt et al., 1995).

A primeira reação do peixe, quando exposto a situação de hipóxia tende a ser a mudança de ambiente, procurando águas com maior concentração de oxigênio dissolvido (Baldisserotto, 2009). Porém, dependendo do grau de hipóxia e da sua duração, os organismos podem desenvolver estratégias que impliquem em mudanças teciduais, fisiológicas e comportamentais para enfrentar essa condição ambiental (Heath, 1995). 


\subsection{Adaptações cardiorrespiratórias à} hipóxia

Para animais aquáticos, a baixa concentração de oxigênio disponível na água faz com que os órgãos respiratórios apresentem adaptações para aumentar a eficiência das trocas gasosas (Baldisserotto, 2009). Estas adaptações incluem $\mathrm{o}$ aumento da velocidade de fluxo de água e estreitamento do espaço entre as lamelas branquiais.

Além disso, os peixes se adaptam aumentando a superficial branquial para atender a demanda por oxigênio. A maior ventilação branquial é conseguida pela elevação da frequência respiratória e por um aumento do volume corrente. $\mathrm{Em}$ peixes que habitam regiões de águas hipóxicas, há maior área branquial do que em peixes de áreas normóxicas, obtidas por longos filamentos e lamelas branquiais (Baldisserotto, 2009).

Uma importante adaptação evolutiva dos peixes foi o sistema de trocas gasosas a partir de em fluxo contracorrente entre a água e o sangue nas lamelas branquiais. Como explica Schmidt-Nielsen (1999) as brânquias dos peixes são constituídas por lamelas em elevado número e muito vascularizadas que estão associadas a filamentos branquiais que, por sua vez, estão ligados aos arcos branquiais. Em cada filamento existe um vaso sanguíneo para entrada de sangue na brânquia e outro para saída. As brânquias localizadas na cavidade opercular entre a faringe e o opérculo, são banhadas por um fluxo contínuo de água que entra pela boca e sai pela fenda opercular. Nas lamelas o sangue circula nos capilares em sentido oposto ao movimento da água que passa na cavidade opercular - mecanismo de contracorrente. Este mecanismo permite 0 aumento do contato entre o sangue cada vez mais oxigenado e a água corrente, cuja pressão parcial do oxigênio é sempre superior à do sangue. Assim a mantém-se o gradiente que assegura a difusão até valores próximos da saturação, aumentando a eficiência da hematose branquial.

A diminuição da pressão parcial de oxigênio na água também pode provocar uma braquicardia, ou seja, uma diminuição do fluxo de sangue pelas brânquias e, consequentemente, maior contato das lamelas com 0 sangue, o que favorece a difusão do oxigênio (Baldisserotto, 2009). A braquicardia diminui a velocidade de passagem do sangue nas brânquias, aumentando o seu tempo de passagem 
pelas lamelas, favorecendo a difusão do oxigênio da água para o sangue.

A hipóxia também pode ativar a liberação de catecolaminas, promovendo a dilatação das arteríolas aferentes e constrição das eferentes. Nesta situação todas as lamelas passariam a receber sangue, aumentando a área disponível para as trocas gasosas (Randall et al., 2000).

Os peixes também podem apresentar um aumento de eritrócitos circulantes, assim como um aumento da afinidade da hemoglobina pelo oxigênio. O que facilita a captação do oxigênio da água é a diminuição dos níveis de GTP e ATP intraeritrocitário (Baldiserotto, 2009).

A carpa comum, por exemplo, apresenta sangue com alta afinidade pela hemoglobina, fato este que aumenta a eficiência da captação de oxigênio na água. Entretanto, essa afinidade dificulta a liberação do oxigênio para os tecidos, o que acaba implicando em redução do nível de atividade desses organismos (Randal, 2000).

Durante a hipóxia aguda pode ocorrer a hiperventilação, com redução de gás carbônico sanguíneo, alcalose respiratória e aumento da afinidade da hemoglobina pelo oxigênio em peixes, de uma forma em geral (Baldisserotto, 2009).

\subsection{Demais adaptações dos peixes à hipóxia}

Peixes que habitam locais onde ocorre a hipóxia devido a existência de cheias periódicas podem realizar diapausa, bem como fazer uso de estruturas acessórias para respiração (Helfan et al., 2009).

$\mathrm{Na}$ diapausa os ovos são depositados em áreas úmidas durante os períodos chuvosos, onde permanecem por um ano. Durante este período, os ovos são expostos ao período de seca, ficando em repouso (diapausa) até que a área seja novamente inundada, quando então ocorre a eclosão das larvas.

Hrbek e Larson (1999), analisando o mecanismo de diapausa em rivulideos, verificaram que 0 desenvolvimento destes peixes pode facilitar sua evolução paralela em habitats temporários, favorecendo a origem múltipla de ciclos de vida anual, por meio de seleção natural imposta por forças ecológicas. Estes peixes depositam seus ovos em épocas chuvosas, sendo encontrados na fase adulta em poucas épocas do ano e atingindo a maturidade sexual rapidamente (Volcan, 2009). 
A segunda característica é a utilização de estruturas acessórias para a respiração, permitindo a captação do oxigênio disponível no meio (Helfan et al., 2009).

O pirarucu (Arapaima gigas), por exemplo, complementa a respiração branquial por meio da captação de oxigênio via bexiga natatória, a qual se comunica com 0 tubo digestivo (Crampton, 1999). Na bexiga natatória existe uma região altamente vascularizada (rete miriabile), que quando em contato com a luz da bexiga preenchida por ar atmosférico, realiza as trocas gasosas. Segundo Crampton (op. cit.), a captação de ar atmosférico é realizada pelo animal ao subir até a superfície da água e abrir a boca, realizando, nesse momento, a respiração suplementar à respiração branquial. Desta forma, o pirarucu é um animal de respiração aérea obrigatória.

A utilização da respiração aérea, no caso do peixe jeju (Hoplerythrinus unitaeniatus), também se dá através da bexiga natatória, entretanto ela é facultativa (Cruz-Hofling et al., 1980).

Tanto o pirarucu quanto o jeju ventilam seus órgãos respiratórios usando a força de uma bomba bucal de forma semelhante a outros peixes, porém com fluxo de ar bidirecional em algumas regiões do trato respiratório. $\mathrm{O}$ ar entra pela boca e é enviado a uma câmara anterior do órgão respiratório por meio do ducto pneumático, onde fica armazenado. Após a expulsão do ar da câmara posterior e saída deste pelo opérculo, o fluxo de ar da câmara anterior segue para a posterior, onde ocorre a troca gasosa (Cahcon e Luchiari, 2011).

O tambaqui

(Colossoma macropomum) quando exposto a águas hipóxicas, projeta o lábio inferior para capturar o oxigênio presente na lâmina d’água (Alves et al., 1999). Com a retomada das condições normais de oxigênio dissolvido na água, essa adaptação morfológica tende a regredir (Val e Val, 1995).

O poraquê, por sua vez, possui a cavidade oral muito vascularizada, possuindo múltiplas dobras e papilas que aumentam a superfície respiratória (Weber et al., 1978).

Outro exemplo de estrutura acessória é observada na Pirambóia (Lepidosiren paradoxa), que possui a bexiga natatória transformada em pulmões pareados. Tal bexiga contém inúmeras paredes muito finas $e$ ricamente vascularizadas, nas quais 0 sangue circula e captura o oxigênio do ar atmosférico (Phelps et al., 1978).

Os bagres (Hoplosternum littorale), por sua vez respiram oxigênio 
atmosférico por meio de uma secção do intestino de paredes delgadas altamente vascularizadas, localizada logo em seguida ao estômago. As paredes desta secção são aglandulares não ciliadas e apresentam vasos sanguíneos grandes na parte externa e densas camadas capilares no interior (Garlick et al., 1978).

Exemplares de carpa do gênero Carassius sp. parecem ser as que mais suportam condições de hipóxia e anóxia, sendo capazes de sobreviver por meses em lagos congelados da Europa e Ásia (Simões, 2008). Quando os níveis de oxigênio caem, a carpa regula a glicólise evitando uma altopoluição pelo incremento dos níveis de lactato, que é convertido em etanol e liberado pelas brânquias (Johnston e Bernard, 1983). Com isso, ela está apta a manter a produção de energia na ausência de oxigênio enquanto houver glicogênio presente no fígado (Nilsson, 1990).

\section{CONCLUSÃO}

Este estudo permitiu observar que os peixes respondem às alterações ambientais relacionadas às variações de temperatura e oxigênio das mais diversas formas. Em ambientes tropicais são capazes de regular seus processos fisiológicos e bioquímicos por meio de elevação de frequências cardíaca e respiratória, além da ocorrência de modificações das características de suas membranas fosfolipidicas. Em ambientes temperados e frios, podem alterar seu metabolismo celular, assim como produzir glicoproteínas anticongelantes e perder $o$ gene codificador da hemoglobina.

Em ambientes hipóxicos, por sua vez, os peixes sofrem inúmeras adaptações cardiorrespiratórias, podendo ocorrer 0 fenômeno de diapausa e o surgimento de estruturas acessórias para a respiração.

Ou seja, à medida que as pressões seletivas se aplicam sobre os peixes estes demonstram possuir grande capacidade adaptativa. Como os ecossistemas aquáticos estão em constante mudança, tais respostas adaptativas dos peixes frente às alterações ambientais acabam sendo um fator-chave para sua sobrevivência como indivíduos e como espécie.

\section{REFERÊNCIAS}

AL-SABTI, K.; METCALFE, C.D. Fish micronuclei for assessing genotoxicity in water. Mutation Research, v. 343, p. 121-135, 1995.

ALVES, M. I. M.; SOUZA, P. C. G.; SILVA, P. R. R. et al. Estratégia respiratória do tambaqui, Colossoma macropomum (Cuvier, 1818), em condições de hipóxia. Revista 
Cientifica de Produção Animal, v. 1, n.2, p. 95-103, 1999.

AVRORA, N. F. The effect of natural adaptations of fishes to environmental temperature on brain ganglioside fatty acid and long chain base composition. Comparative

Biochemistry Physiology, v. 78, n. 4, p. 903-909, 1984.

BALDISSEROTTO, B. Fisiologia de peixes aplicada à piscicultura. São Paulo, 2009, 350 p.

BLACK, N. A.; VOELLMY, R.; SZMANT, A. M. Heat shock protein induction in Montastraea faveolata and Aiptasia pallida exposed to elevated temperatures. Biological Bulletin, v. 188, p. 234-240, 1995.

BREAU, C.; CUNJAK, R. A.; BREMSET, G. Age-specific aggregation of juvenile Atlantic salmon Salmo salar at cool water sources during high temperature events. Journal of Fish Biology, v. 71, p. 1179-1191, 2007.

BREER, H.; RAHMANN, H. Involvement of brain gangliosides in temperature adaptation of fish. Journal of Thermal Biology, v. 1, p. 233- 235, 1976.

BUCKLEY, B. A.; OWEN, M. E.; HOFMANN, G. E. Adjusting the thermostat: the threshold induction temperature for the heatshock response in intertidal mussels (genus Mytilus) changes as a function of thermal history. The Journal of Experimental Biology, v. 204, p. 3571-3579, 2001.

BRIAN, J. V.; HARRIS, C. A.; RUNNALLS, T. J. et al. Evidence of temperature-dependent effects on the estrogenic response of fish: implications with regard to climate change. Science of the Total Environment, v. 397, p. 72-81, 2008.

BROWN, H. M.; BRIDEN, A.; STOKELL, $\mathrm{T}$. et al. Termotolerance and HSP70 profiles in adult and embryonic California native oyster, Ostreola conchaphila
(Carpentes, 1857). Journal of Selfish Research, v. 23, n.1, p. 135-141, 2004.

CAHCON, D. M. M.; LUCHIARI, A. C. Peixes. Disponível em http://geefaa.com/painel/pdf/peixesfisioc omp.pdf. Acesso em 05 de junho de 2012.

CARNEIRO, F. M. Análise do estudo de impacto ambiental e da qualidade da água - o caso açude atalho - brejo santo, Ceará. 2002. Ceará, 198 f. Dissertação (Mestrado em Desenvolvimento e Meio Ambiente) Curso de Pós-graduação em Desenvolvimento e Meio Ambiente, Universidade Federal do Ceará.

CASAGRANDE, C. A.; MOURA, J. M. S.; MARCONDES A. et al. Efeitos Naturais e Antrópicos nas Alterações dos Teores de Oxigênio Dissolvido: Uma Comparação Entre as Bacias do Rio Amazonas e Piracicaba. Revista Brasileira de Recursos Hídricos, v. 11, n. 4, p. 221-231, 2006.

CRAMPTON, W. G. R. Os peixes da reserva Mamirauá: diversidade e história natural na planície alagável da Amazônia. In: Estratégias para manejo de recursos pesqueiros em Mamirauá. Editado por Helder L. Queiroz, William G.L. Crampton. Brasilia: Sociedade Civil Mamiraua: CNPq 208 p. 1999.

$\mathrm{CHO}$, E. S.; JEONG, H. D. Effect of environmental impact to molecular expression of heat-shock protein (HSP70) in oyster Crassostrea gigas from Gamak bay, Korea. Journal of Environmental Biology, v. 33, p. 609615, 2012.

CHORESH, O.; RON, E.; LOYA, Y. The 60-k Da Heat Shock Protein (HSP60) of the Sea Anemone Anemonia viridis: A potential early warning system for environmental changes. Marine Biotechnology, v. 3, p. 501-508, 2001. 
CURRIE, S.; TUFTS, B. L. Synthesis of stress protein 70 (Hsp70) in rainbow trout (Oncorhynchus mykiss) red blood cells. Journal of Experimental Biology, v. 200, p. 607-614, 1997.

CRUZ-HOFLING, M. A.; CRUZLANDIM, C.; PATELLI, A. S. Comparações morfológicas e histoquímicas de bexiga natatória de peixes teleósteos de respiração aquática e respiração aérea. Acta Amazonica, v. 10, n.1, p. 147-155, 1980.

DONG, Y.; SOMERO, G. N. Temperature adaptation of cytosolic malate dehydrogenases of limpets (genus Lottia): differences in stability and function due to minor changes in sequence correlate with biogeographic and vertical distributions. Journal of Experimental Biology, v. 212, p. 169177, 2008.

\section{ESTEVES $<1998$}

FABBRI, E.; VALBONESI, P.; FRANZELLITTI, S. HSP expression in bivalves. Information Systems Journal, v. 5, p. 135-161, 2008.

FERNANDES, F. A. Estresse osmótico: proteínas de estresse e balanço oxidativo em Neohelice granulata (Crustacea, Decapoda, Veronidae). 2010. 175 f. Tese (Doutorado em Ciências Biológicas) Universidade Federal do Rio Grande do Sul.Porto Alegre.

FIORUCCI, A. R.; FILHO, E. B. A importância do oxigênio dissolvido em ecossistemas aquáticos. Química e sociedade, n. 22, 2005.

GARLICK, R. L.; BUNN, H. F.; FYHN, H. $J$. et al. Estudos funcionais dos componentes separados da hemoglobia de um bagre de respiração aérea, Hoplosternum littoralle (Hancock). Supl. Acta Amazônica, v. 8, n. 4, p. 293-303, 1978.
GOLDSTONE, J. V. Environmental sensing and response genes in cnidaria: the chemical defensome in the sea anemone Nematostella vectensis. Cell biology and Toxicology, v. 24, n. 6, p. 483-502, 2008.

GOULART, M.; CALLISTO, M. Bioindicadores de qualidade de água como ferramenta em estudos de impacto ambiental. Revista da FAPAM, v. 2, n. 1, 2003.

HEATH, A. G. Water pollution and fish physiology. $2^{\text {a }}$ ed. 1995. 359p.

HELFAN, G. S.; COLLETTE, B. B.; FACEY, D. E. et al. The diversity of fishes: biology, evolution and ecology. $2^{a}$ ed. $2009.737 \mathrm{p}$.

HOCHACHKA, P. W.; SOMERO, G. N. Strategies of Biochemical Adaptation. W.B. Saunders, Philadelphia. 1973.353 p.

HOCHACHKA, P.; SOMERO, G. Biochemical Adaptation, Mechanism and Physiological Evolution. New York: Oxford University Press, 2002.438 p.

HRBEK, T.; LARSON, A. The evolution of diapause in the killifish family Rivulidae (Atherinomorpha, Cyprinodontiformes): a molecular phylogenetic and biogeographic perspective. Evolution, v. 53, p. 12001216, 1999.

IWAMA, G. K.; THOMAS, P. T.; FORSYTH, R. B. et al. Heat shock protein expression in fish. Reviews in Fish Biology and Fisheries, v. 8, p. 3556, 1998.

IWAMA, G. K.; VIJAYAN, M. M.; FORSYTH, R. B.et al. Heat shock proteins and physiological stress in fish. American Zoologist, v. 39, p. 901-909, 1999.

IWAMA, G. K.; AFONSO, L. O. B.; TODGHAM, A. et al. Are HSPS suitable for indicating stressed states in fish? 
Journal of Experimental Biology, v. 207, pg. 15-19, 2004.

JOHNSON, A. C.; ACREMAN, M. C.; DUNBAR, M. J. et al. The British river of the future: How climate change and human activity might affect two contrasting river ecosystems in England. Science of the Total Environment, $v$. 407, p. 4787-4798, 2009.

JOHNSTON, I. A.; BERNARD, L. M. Utilization of the ethanol pathway in carp following exposure to anoxia. Journal of Experimental Biology, v, 104, p. 73-78, 1983.

LACOSTE, A.; JALABERT, F.; MALHAM, S. K. et al. Stress and stressinduced neuroendocrine changes increase the susceptibility of juvenile oysters (Crassostrea gigas) to vibrio splendidus. Applied and Environmental Microbiology, v. 76 , n. 5, p. 23042309, 2001.

LIEPELT, A.; KARBE, L.; WESTENDORF, J. Induction of DNA strand breaks in rainbow trout Oncorhynchus mykiss under hypoxic and hyperoxic conditions. Aquatic Toxicology, v. 33, p. 177-18, 1995.

LOHBECK, K. T.; RIEBESELL, U. L. F.; REUSCH, T. B. H. Adaptive evolution of a key phytoplankton species to ocean acidification. Nature Geoscience, v.5, p.346-351, 2012.

MARIANO, W. S.; OBA, E. T.; SANTOS, L. R. B. et al. Respostas fisiológicas de jeju, Hoplerythrinus unitaeniatus (Characiformes, Erythrinidae) expostos ao ar atmosférico. Revista brasileira de saúde e produção animal, v.10, p. 210-223, 2006.

MORAIS, M. G.; COSTA, J. A. V. Perfil de ácidos de microalgas cultivadas com dióxido de carbono. Ciências e Agrotecnologia de Lavras, v. 32 , n. 4, p. 1245-1251, 2008.

MUNDAY, P. L.; LEIS, E. J. M.; LOUGH, E. J. M. et al. Climate change and coral reef connectivity. Coral Reefs, v. 28, p. 379-395, 2009.

NILSSON, G.E. Long-term anoxia in crucian carp - changes in the levels of amino-acid and monoamine neurotransmitters in the brain, catecholamines in chromaffin tissue, and liver-glycogen. Journal of Experimental Biology, v. 150, p. 295320, 1990.

PERES-NETO, P.R. Alguns métodos e estudos em ecomorfologia de peixes de riachos. Oecologia, v. 6, p. 209-236, 1999.

PHELPS, C.; FARMER, M.; FYHN, H. J. et al. Equilíbrio e cinética de união de oxigênio e monóxido de carbono a hemoglobina do peixe pulmonado sul americano Lepidosiren paradoxa. Supl. Acta amazônica, v. 8, n. 4, p. 185-190, 1978.

POUGH, E. H.; JANIS, C. M.; HEISER, J. B. A vida dos vertebrados. $3^{\mathrm{a}} \mathrm{ed}$, Atheneu Editora São Paulo Itda., São Paulo. 2003. 699p.

POWERS, D. A.; MARTIN, J. O.; GARLICK, R. L. et al. O efeito da temperatura sobre 0 equilíbrio de oxigênio das hemoglobinas de peixe em relação à variabilidade térmica ambiental. Supl. Acta Amazônica, v. 8, n. 4, p. 167-172, 1978.

PRISCO, G.; PISANO, E.; CLARKE, A. Fishes of Antarctica, a biological overview. Springer, 1998. $363 \mathrm{p}$.

PROSSER, C. L. Molecular mechanisms of temperature regulation. New York: Amer. Assoc. Advancement of Science, 1967.

RANDALL, D.; BURGGREN, W.; FRENCH, K. Fisiologia animal, mecanismos e adaptações. 4 ed. Editora Guanabara Koogan. S. A. 2006. $729 p$.

RAVAUX, J.; GAILL, F.; BRIS, N. et al. Heat-shock response and temperature 
resistance in the deep-sea vent shrimp Rimicaris exoculata. Journal of Experimental Biology, v. 206, p. 23452354, 2003.

Ravaux, 2007

ROOTS, B. Phospholipids of goldfish (Carassius auratus L.) brain: the influence of environmental temperature. Comparative Biochemistry and Physiology, v. 25, p. 457-466, 1968.

SANTANA, G. P. 2008. Poluição aquática. Disponível em http://www.cq.ufam.edu.br/Artigos/poluic ao_aquatica/poluicao_aquatica.html Acesso em 07 de junho de 2012.

SCHMIDT-NIELSEN, K. Fisiologia Animal - Adaptação e Meio Ambiente. Editora Guanabara, São Paulo.1999. 620p.

SIMÕES, E. Respirometria: Metodologia para determinação, em tempo real, do consumo de oxigênio em função do tempo para organismos aquáticos e influência da água magnetizada na respirometria de Carassius sp. (Kinguio). Monografia de engenheiro em aquicultura. 2008. 41 f. Universidade Federal de Santa Catarina, Florianopolis.

TOMANEK, L. The heat-shock response: its variation, regulation and ecological importance in intertidal gastropods (genus Tegula). Integrative and Comparative Biology v. 42, pg. 797-807, 2002.

Tewkbury et al, 2008

VAL, A. L.; ALMEIDA-VAL, V. M. F. Fishes of the Amazon and their environments. Physiological and Biochemical Features, 1995.

VERDE, C.; PARISI, E.; PRISCO, G. The evolution of thermal adaptation in polar fish. Gene, v. 385, p. 137-14, 2006.
VERDE, C.; GIORDANO, D.; RUSSO, $R$. et al. Evolutionary adaptations in antarctic fish: the oxygen-transport system. Oecologia Australis, v. 15, n. 1, p. 40-50, 2011.

VOLCAN, M. V. Crescimento e fecundidade do peixe anual Austrolebias nigrofasciatus (Cyprinodontiformes: Rivulidae) sob condições de laboratório. 2009. $59 \mathrm{f}$. Dissertação (Mestrado em aquicultura) Fundação Universidade Federal do Rio Grande, Rio Grande.

WEBER, R. E.; WOOD, S. C.; DAVIS, B. J. Aclimatação do peixe de respiração aérea facultativa a água hipóxica: afinidade pelo oxigênio do sangue e agentes alostéricos. Suplementos Acta amazônica, v. 8, n.4, p. 167-172, 1978.

WOHRMANN, A. P. A. Antifreeze glycopeptides and peptides in Antarctic fish species from the Weddell Sea and the Lazarev Sea. Marine Ecology Progress Series, v. 130, p. 47-59, 1996. 